\title{
Los Cantores Africanos. Llegada y recepción del blackface minstrelsy en la segunda mitad del siglo XIX en Chile (1860)
}

\author{
Los Cantores Africanos. Arrival and reception of the Blackface \\ Minstrelsy in the second half of the 19th century in Chile \\ (1860)
}

\author{
por \\ Daniel Domingo Gómez \\ Universidad de Santiago de Chile, Chile \\ daniel.domingo.g@gmail.com
}

\begin{abstract}
En septiembre de 1860 arribó a Chile una compañía teatral norteamericana, los "Cantores Africanos" (Ethiopian Minstrels), la cual actuó en el Teatro de la Victoria de Valparaíso y en el Teatro Municipal de Santiago. Este artículo analiza, por medio de los diarios El Mercurio de Valparaíso y El Ferrocarril, cómo fue su llegada, así como el programa que representaron y su recepción chilena. Sostenemos que esta compañía corresponde a la primera llegada documentada del blackface minstrelsy a Chile. Por ello, en un primer momento contextualizamos esta forma de entretenimiento popular estadounidense. Seguidamente, tratamos su llegada en el Chile decimonónico. Nuestra hipótesis es que, si bien no tuvo gran impacto en la sociedad local, esta representación artística reforzó tanto el sentido de alteridad racial como reafirmó una superioridad estética y musical de la audiencia allí congregada.
\end{abstract}

Palabras clave: Chile, Siglo XIX, Blackface, Minstrel, Teatro, Cantores Africanos, Ethiopian Minstrels.

In September 1860, an American theater company arrived in Chile, "Cantores Africanos" (Ethiopian Minstrels), which performed at the Victoria Theater in Valparaiso and the Municipal Theater of Santiago. This article analyzes, through the newspapers El Mercurio de Valparaiso and El Ferrocarril, how their arrival was, as well as the program they performed and their Chilean reception. We propose that this company corresponds to the first documented arrival of the Blackface Minstrelsy to Chile. Therefore, initially we contextualize this form of popular American entertainment. Next, we examine its arrival in 19th century Chile. Our hypothesis is that, although it did not have a great impact on local society, this artistic representation reinforced both the sense of racial otherness and reaffirmed an aesthetic and musical superiority of the audience gathered there.

Keywords: Chile, 19th century, Blackface, Minstrel, Theater, Cantores Africanos, Ethiopian Minstrels. 


\section{INTRODUCCIÓN ${ }^{1}$}

En 1948, Eugenio Pereira Salas redactó una pequeña crónica para la Revista Musical Chilena titulada: "El rincón de la historia. La llegada de los 'Negro Spirituals' a Chile" (Pereira Salas 1948). De este modo el historiador, que unos años antes había cimentado las bases de la historia musical nacional con Los origenes del arte musical en Chile (1941), informaba de la llegada de una compañía afronorteamericana, la que habría actuado en 1859 en la ciudad de Valparaíso y en 1860 en el Teatro Municipal de Santiago.

Según la afirmación de Pereira Salas, un conjunto compuesto por siete miembros, los Ethiopian Minstrels, interpretó un variado repertorio en el que se combinaban spirituals y baladas al son del banjo, junto con bailes y representaciones teatrales dentro de un escenario que, durante una parte del acto, simulaba ser una plantación de algodón².

Unos años más tarde, Eugenio Pereira Salas se retractó en Historia de la música en Chile (1850-1900). En concreto, ajusta la fecha de su llegada para 1860 pero, además, reconoce que este espectáculo teatral fue ejecutado por minstrels, quienes presentaron un repertorio "mixto de canciones y danzas, inspiradas en melodías negras, aun cuando todos sus intérpretes eran artistas de raigambre sajona" (Pereira Salas 1957: 119). Si bien no aportó mayor profundidad acerca del devenir de esta compañía por tierras chilenas, ni tampoco mencionó las fuentes que le permitieron entregar esta nueva información, sí matizó: "en realidad no se trata de los spirituals sino de los minstrels" (Pereira Salas 1957: 120).

Posteriormente, Álvaro Menanteau (2006: 24-26) citó la primera versión entregada por Eugenio Pereira Salas y la presentó como la "prehistoria del Jazz". No obstante, y pese a que muestra una crónica publicada en El Mercurio de Valparaíso de 1860, parece ser que su búsqueda de fuentes no le aportó total claridad en sus postulados, pues informa, "no ha sido posible confirmar a cabalidad la información expuesta por Pereira Salas" (Menanteau 2006: 24).

Asimismo, Víctor Rondón (2014: 60-61) cuestionó brevemente la originalidad afrodescendiente de esta expresión artística, planteando la hipótesis de que la escena estaría representada por músicos blancos caracterizados.

Teniendo en cuenta entonces la vaga y confusa información que circulaba acerca de esta compañía, el impulso para iniciar esta investigación fue conocer, con la mayor claridad posible, el verdadero carácter de este grupo de artistas estadounidenses, así como indagar en la originalidad del repertorio que mostraron en el Chile decimonónico. Es necesario reconocer que, debido a una investigación anterior en la que abordamos la música durante el periodo de la esclavitud en Estados Unidos (Domingo 2017), partimos con varias consideraciones previas que nos ayudaron a poner en duda y cuestionar determinados planteamientos.

1 Este artículo se enmarca en una investigación realizada en el curso optativo "Diplomacia cultural, música y relaciones interamericanas" impartido por la Dra. Carol Hess en 2019, para el Magíster en Musicología Latinoamericana de la Universidad Alberto Hurtado, Chile. Agradezco su ayuda y motivación por iniciarlo. Asimismo, agradezco las recomendaciones y consejos recibidos por la Dra. Daniela Fugellie y por la recomendación bibliográfica aportada por el Dr. Juan Pablo González y por Felipe Caballero. Esta investigación cuenta con el apoyo de ANID-Subdirección de Capital Humano/ Doctorado Nacional/2021- 21210937.

2 Es interesante observar que, para la fecha que se menciona, estas plantaciones todavía eran trabajadas con mano de obra esclavizada en los estados del sur del país. Si bien Abraham Lincoln proclamó su emancipación en enero de 1863, la abolición no se hizo efectiva hasta el final de la Guerra Civil, en 1865. 
En primer lugar, hacia 1860 todavía no se habían publicado ni investigaciones ni recopilaciones serias de los spirituals afronorteamericanos, si bien aparecían mencionados y descritos parcialmente en multitud de diarios de viaje y de plantaciones, o en autobiografías de esclavos fugados como las de Frederick Douglass $(1846 ; 1855)$, Harriet Tubman ${ }^{3} \mathrm{o}$ Solomon Northup (1859), entre otros.

El primer trabajo que recopiló un gran número de canciones sacras de época esclavista fue Slave Songs of the United States, publicada en 1867 por los abolicionistas William Francis Allen, Lucy McKim Garrison y Charles Pickard Ware. Estos pioneros, pese a no ser expertos folcloristas, antropólogos o musicólogos, se mostraron preocupados por preservar esta música ante los peligros del cambio histórico. Es significativo cómo se inicia esta obra:

La capacidad musical de la raza negra ha sido reconocida por tantos años que es difícil explicar por qué no se ha hecho hasta ahora ningún esfuerzo sistemático para recoger y conservar sus melodías (Allen, Garrison y Ware 1867: i) ${ }^{4}$.

Y es que muchas de las canciones presentadas como "música negra" en programas de teatro, y que también entraban dentro del mercado de circulación de partituras bajo el nombre de "canciones de plantación", no eran más que creaciones realizadas para ser representadas por compañías de blackface minstrelsy, es decir, por compañías "blancas" que, ennegreciendo su rostro con corcho quemado, caricaturizaban la cultura de los esclavos afroamericanos del Sur.

Otro elemento que nos remitía a este tipo de espectáculos es que, para ese mismo periodo, nombres como Christy's Minstrels o compañías con el calificativo de Ethiopian, como los Ethiopian Serenaders, Ethiopian Minstrels o Ethiopian Delineators, correspondían a términos genéricos que utilizaban un gran número de conjuntos blackface (Legnini 2011: 52).

La música religiosa rara vez aparecía en los minstrel shows, y menos en una fecha tan temprana. No fue sino hasta 1871 cuando los Fisk Jubilee Singers, un conjunto a cappella afronorteamericano, incluyó spirituals en sus programas de conciertos, mientras recorrían las carreteras de Estados Unidos para recaudar fondos en beneficio de la Universidad de Fisk, en Nashville. Tal fue su éxito, con más de veinte mil dólares recaudados, que posteriormente realizaron una gira internacional por Europa, actuando incluso ante la reina Victoria en 1873 (Gioia 2010: 34-37; Graham 2018: 17-47).

Por medio de anuncios de actuaciones de teatro y crónicas locales publicadas en dos diarios, El Mercurio de Valparaíso y El Ferrocarril, analizaremos la llegada y la recepción en Chile de los Ethiopian Minstrels en la segunda mitad del siglo XIX. En un primer momento, abordaremos el surgimiento de estas compañías, así como la compleja relación que se ha producido al analizar la cultura afroamericana y el surgimiento y la performance de esta forma de entretenimiento popular estadounidense.

Seguidamente, trataremos acerca de la internacionalización de la cultura popular norteamericana, que inicia ya en la segunda mitad del siglo XIX, situándola dentro del contexto chileno. Por último, analizaremos cómo es que, debido a que el Chile del periodo decimonónico poseía elementos socioculturales muy distintos a los norteamericanos-además de la

3 Algunas autobiografías de personas esclavizadas, como la de Harriet Tubman, fueron escritas por abolicionistas de los estados del norte del país (Bradford 1886). No obstante, se presentaron como trabajos fidedignos realizados juntamente con las personas que habían vivido bajo el yugo de la esclavitud. No es la intención de este trabajo abordar su veracidad o cómo trabajar estas fuentes, sin embargo, aparecen spirituals, así como el contexto en el que se desarrollaban.

4 The musical capacity of the negro race has been recognized for so many years that it is hard to explain why no systematic effort has hitherto been made to collect and preserve their melodies (la traducción es nuestra). 
diferencia del lenguaje-, se produjeron condiciones específicas para la recepción chilena, que ocasionó modificaciones en el repertorio y en el programa clásico de los minstrel shows.

Nuestra hipótesis es que la actuación de los Ethiopian Minstrels correspondió a una compañía blackfacey, analizando su llegada y recepción, defendemos que tuvo poco impacto en el Chile decimonónico.

\section{CORCHO QUEMADO Y CULTURA POPULAR EN NORTEAMÉRICA}

Es cierto que, generalmente, la sociedad estadounidense a mediados del siglo XIX desconocía por completo las canciones, tanto seculares como profanas, que realizaban las personas esclavizadas. No obstante, la aparición de personajes que se caracterizaban como tal no era nada nuevo para el público. Por ejemplo, así como afirma Ted Gioia (2010: 32-34), durante el período de las trece colonias, espectáculos de curanderos y de vendedores ambulantes eran amenizados con comediantes que llevaban el rostro tiznado de negro, e incluían en sus representaciones números con instrumentos como el banjo.

Posteriormente, después de la independencia de EE.UU., algunos personajes generaron grandes beneficios y fama. El primero está documentado en 1827, cuando George Washington Dixon oscureció su rostro y danzó al ritmo de "Coal Black Rose", "My Long Tailed Blue" o "Zip Coon" (Cockrell 2012: 55-62; Green 1970). Poco tiempo después, Thomas D. Rice alcanzó popularidad en la década de 1830 con su número "Jump Jim Crow", en el cual supuestamente imitaba de manera fidedigna un baile que había visto hacer a un esclavo de Kentucky (Mahar 1999: 101-103; Toll 1977: 28) ${ }^{5}$. Fue asimismo uno de los pioneros en internacionalizar estos actos, pues viajó con su afamado número a Londres en 1836. Más tarde, estas interpretaciones fijaron dos estilos clásicos en la comedia "de la cara negra" norteamericana: la vida rural de la plantación y el dandi negro urbano (ver Figura 1).

Este tipo de representaciones comenzaron a ganar notoriedad y, si bien todavía no ocupaban números completos dentro de espectáculos nocturnos, se utilizaban como teloneros y para rellenar "huecos" en obras de teatro y en números circenses. No será sino hasta 1843 cuando los Virginia Minstrels presenten en Nueva York el primer acto completo documentado de blackface minstrelsy (Waterhouse 1985: 1-2). Ya para finales de la década de 1840, observando el éxito producido, surgieron un gran número de compañías en Estados Unidos como, por ejemplo, los Christys Minstrels o los Ethiopian Seneraders, entre muchos otros.

Los minstrel shows se presentaron ante el público como un espectáculo que, generalmente dividido en dos o tres partes, mostraba la "auténtica" vida cotidiana y cultural de los afroamericanos del país (Lott 2013; Mahar 1999). Esta manifestación artística eclosionó como una forma de entretenimiento tremendamente popular que combinaba tanto "canciones sentimentales”, coros y baladas, así como bailes cómicos y algún monólogo. Los artistas se sentaban en disposición de semicírculo, con la cara impregnada de corcho quemado, con pelucas, y vestían llamativos atuendos.

5 Otras versiones aseguran que Thomas Rice copió la rutina de un artista callejero discapacitado (Scott 2012: 51). En todo caso, es significativo que un conjunto de leyes estatales de Estados Unidos emanadas durante el período de la Reconstrucción y que promovían la segregación racial, fueran conocidas bajo el nombre de Jim Crow. 


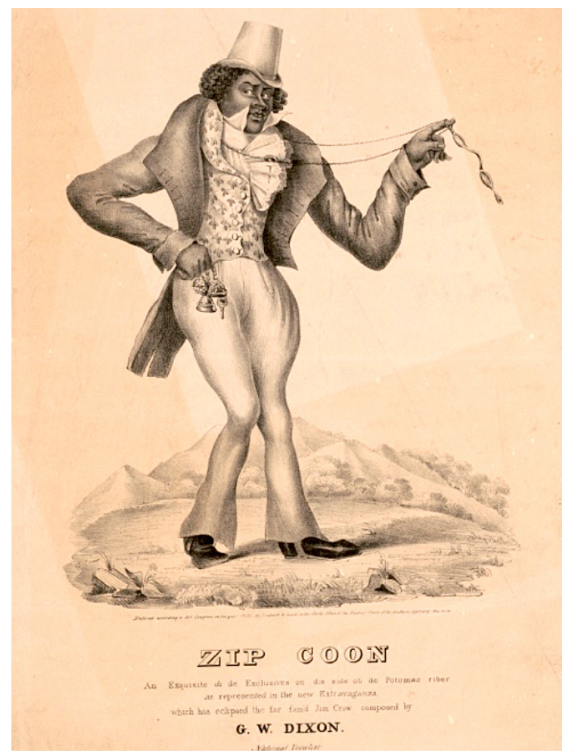

Figura 1: Dandi “Zip Coon”. Portada de una partitura de música. Endicott \& Swett, 1834. Fuente: Endicott \& Swett, L. (ca. 1834) Zip Coon. [Fotografía] Recuperada de: Library of Congress, https://www.loc.gov/item/00650780/ [acceso: 19 de mayo, 2021].

De esta forma imitaban las posturas y su andar, así como sus costumbres y modales, además del caricaturizado "dialecto negro" de los esclavos del sur ${ }^{6}$. También cantaban, bailaban y tocaban instrumentos, como el banjo, la pandereta, el violín, o los huesos (al estilo de una castañuela) y pronunciaban discursos, acertijos y juegos de palabras para vehiculizar el sentido del humor del público ${ }^{7}$.

Sin embargo, esas pretensiones de autenticidad acerca de la representación de la cultura afronorteamericana han sido cuestionadas y rechazadas, ya que esta gran tradición de "comedia, canción y baile negro" no eran más que composiciones y elaboraciones realizadas por blancos del noroeste del país, donde se establecía un modelo relacional con el que las masas estadounidenses "blancas" podían conformar un sentido de identidad positivo y superior.

Estudios recientes, además, descubren múltiples influencias dentro de este espectáculo de entretenimiento, pues bebe de la tradición de la balada inglesa y de géneros populares como el circo y el ballet. De igual forma, debido a la gran llegada de inmigrantes europeos,

6 Salvando las distancias, esta apropiación e incorporación de la alteridad étnico-racial afroamericana, donde el lenguaje se vuelve fundamental para representar la diferencia, también aparece en Hispanoamérica desde época colonial. Un ejemplo son los villancicos de negros, negrillas o guineos, los que fueron compuestos para ser cantados e interpretados durante la festividad de Navidad y donde se simulaba el carácter, la fonética y el habla bozal de los esclavizados africanos (Daponte 2019; Morales 2010).

7 Para profundizar más acerca del origen y las representaciones blackface, recomendamos a Lott 2013, Mahar 1999 y Toll 1977. 
se defiende una marcada herencia de música de baile escocesa e irlandesa (Davis 2013: 45-46; Scott 2012: 149).

A pesar de ello, por medio de lo que hoy se tildaría como apropiación indebida, también se descubren elementos y tópicos afronorteamericanos, como el canto responsorial, el uso de slides, el pulso constante y estable que interactúa con el primer plano rítmico, o las formas pentatónicas. Y es cierto que artistas y compositores viajaron y permanecieron algún tiempo realizando alguna especie de "trabajo de campo" en las ciudades y las plantaciones del sur. Así, en temáticas y textos de algunas canciones aparecen también referencias de la rica tradición vernácula afronorteamericana (Scott 2012: 149-154).

Este "ir y venir" cultural no significa que se pueda ignorar la cuestión de la apropiación cultural, sino que se debe considerar como una cuestión de relaciones desiguales de poder en el dominio social y no como una cuestión abstracta de estética musical. El músico blanco pudo definir la naturaleza de la música negra y dominar su recepción, dejando al músico negro con una identidad en desacuerdo con su subjetividad ${ }^{8}$ (Scott 2012: 154).

Por estos motivos, en 1848 Frederick Douglass, esclavizado fugado de Maryland que pronto ganó notoriedad dentro de la causa abolicionista debido a su gran oratoria, se mostró muy crítico con los intérpretes "de cara negra”, a los que calificó como "la escoria sucia de la sociedad blanca que nos ha robado un cutis que la naturaleza les niega, para ganar dinero y complacer el gusto corrupto de sus conciudadanos blancos9" (Douglass, en Davis 2013: 43).

\section{UN ESPEJO DISTORSIONADO}

A pesar de ello, investigadores y académicos contemporáneos observan en los minstrel shows una relación extremadamente compleja donde se proyecta un doble código pues, si bien expandieron estereotipos y jerarquías racistas, al mismo tiempo podían sumarse a la causa abolicionista o incorporar una abierta crítica social en contra de los valores burgueses.

Como ejemplo, dentro del amplio repertorio del blackface, encontramos canciones donde se retrataba a las personas esclavizadas como infantiles, felices, dependientes e inútiles. Así, en "Massa's In De Cold Cold Ground", compuesta por Stephen Foster, una persona llora y se lamenta profundamente por el fallecimiento de su "amo":

Massa made de darkeys love him, Cayse he was so kind,

Now dey sadly weep above him, [...]

I try to drive away my sorrow

Pickin' on de old banjo ${ }^{10}$
El amo hizo que los "negros" lo amaran

Porque él era muy amable

Ahora lloran tristemente sobre él

[...]

Intento alejar mi pena

Toco el viejo banjo

8 This cultural "to-ing and fro-ing" does not mean that the question of cultural appropriation may be ignored but, rather, that it should be seen as a matter of unequal power relations in the social domain rather than as an abstracted question of musical aesthetics. The white musician was able to define the nature of black music and dominate its reception, leaving the black musician with an identity at odds with his or her subjectivity (la traducción es nuestra).

9 The filthy scum of white society, who have stolen from us a complexion denied to them by nature, in which to make money, and pander to the corrupt taste of their white fellow citizens (la traducción es nuestra)".

10 Observamos también cómo era representado el caricaturizado "dialecto negro", que aparecía tanto en las publicaciones de partituras de música como en los actos encima de un escenario. 
Pero, por otra parte, dentro de las "escenas de los plantíos", los propietarios de esclavos podían ser representados como incapaces de ensillar a los caballos, mientras tropezaban con herramientas agrícolas o perseguían cómicamente a los animales sin resultado alguno. De igual modo, mostraban cómo las personas esclavizadas subvertían el rígido sistema de plantación, pues preparaban el té del "amo" con hojas amargas o golpeaban su abrigo cuando él no miraba (Toll 1971: 42) ${ }^{11}$.

En síntesis, según la historiografía actual, la performance de los blackface minstrelsy puede analizarse desde un punto de vista integracionista, ligado a la filiación de clase trabajadora, al parodiar a las oligarquías y a la burguesía. También, puede estudiarse la difusión masiva de elementos de una cultura afroamericana que, pese a estar controlada por blancos, "paradójicamente resultó en el ennegrecimiento de Norteamérica" (Lott 2013: 102) 12. Pero, del mismo modo, debe observarse como una actuación tremendamente segregacionista y racista que refuerza el statu quo de la sociedad blanca, presentándola desde una clara superioridad racial, mientras se deshumaniza y homogeniza a una parte de la población que, desde su esclavización y traslado forzoso al continente americano, había sufrido un violento proceso de transculturación. En todo caso, no se puede ignorar su considerable impacto en la cultura popular ${ }^{13}$.

Por último, queremos añadir algunas consideraciones. Es cierto que el surgimiento y la presentación de los minstrel shows proyectaron mensajes y preocupaciones que estaban notoriamente interconectadas con la ideología política, con la tensión producida entre los diferentes modelos económicos de los estados del norte y del sur, así como con la formación de clase que se llevaba a cabo durante el periodo anterior y posterior a la Guerra Civil.

Sin embargo, incluso cuando estas compañías mostraron posiciones más cercanas al abolicionismo y trasladaron sus críticas sociopolíticas dentro del escenario, lo hicieron al margen de la población afroamericana. Las compañías blackface monopolizaron los principales teatros y circuitos artísticos nacionales e internacionales ${ }^{14}$, además de incorporar técnicas publicitarias modernas en anuncios de periódicos locales. A ello se debe sumar el control de la composición, distribución y comercialización de partituras dentro de la circulación del sistema de mercado (Waterhouse 1985: 6-7).

Además, la representación "del corcho quemado" articuló un imaginario racial que, bajo el modelo y la subjetividad del dominador, produjo una inferioridad y subalternidad

11 En esta misma línea, Eric Lott propone analizar el inconsciente que está detrás del espectáculo del blackface, situándolo dentro de su contexto histórico, social, económico y político. Por esta razón, lo define como un "espejo distorsionado" que refleja las preocupaciones y los valores de los hombres blancos de clase trabajadora, y donde se presentan desplazamientos y contradicciones que fueron fundamentales para definir aspectos relacionados con la raza, clase y género (Lott 2013: 8). Sugiere, además, que los primeros artistas se sintieron atraídos por la música y la cultura negra, pero para representarla, emplearon formas satíricas debido al temor y ansiedad que también les suscitaba, y así poder controlar y expropiar esa cultura (Lott 2013: 62).

12 Ironically, contributed to a blackening of America (la traducción es nuestra).

13 Para profundizar acerca de la relación que se produce entre la representación de los blackface minstrelsy y la verdadera cultura afronorteamericana, ver Johnson 2012a; Lott 2013; Mahar 1999 y Toll 1977.

14 William Henry Lane, conocido popularmente como Maestro Juba, fue una de las notables excepciones de artistas afronorteamericanos que ganaron fama durante el periodo anterior a la Guerra Civil, convirtiéndose en el único bailarín que actuó en "teatros reservados para blancos" a mediados de la década de 1840 (Lott 2013: 117). Asimismo, en 1848 viajó a Londres con el conjunto The Ethiopian Serenaders (Johnson 2012b:73-82). 
que deformó al Otro, y desembocó en una falsa relación determinista entre unos supuestos rasgos físicos y unas características culturales que, por lo demás, ellos mismos habían determinado.

Y es que, por medio del minstrel show, se creó una caricatura del afronorteamericano universalmente aceptable, se proporcionó un molde, y se instaló de forma tan convincente, que cualquiera que durante el siglo XIX quisiera realizar una representación humorística "negra" tenía que adoptar el patrón minstrel, y ello incluyó a los propios afroamericanos. Este hecho generó varias secuelas que perduraron en el tiempo, tanto así que incluso el propio Louis Armstrong debió utilizar muecas y gestos que derivan del blackface en sus conciertos (Brown 2013; Scott 2012: 154).

Otra de esas consecuencias es la instalación y expansión de ciertos estereotipos y prejuicios que, generalmente, fueron utilizados para describir a las poblaciones tanto africanas como afroamericanas: pereza, de carácter alegre o melancólico, facilidad en el ritmo, la percusión y la danza, etc. Entonces, no es casual que, más de medio siglo después de la primera llegada de los Ethiopian Minstrels a Chile, Eugenio Pereira Salas inicie la exposición de su andadura con esta afirmación:

En el repertorio actual de los conciertos de música vocal nunca falta la sentida expresión de una melodía negra, rítmica y lastimera, llena de la hondura de sentimiento de una raza que ha confiado a la música, más que a cualquier otro arte, sus profundas emociones (Pereira Salas 1948: 68).

\section{LA INTERNACIONALIZACIÓN DE LA CULTURA POPULAR NORTEAMERICANA. LOS “CANTORES AFRICANOS” EN EL CHILE DECIMONÓNICO}

El espectáculo proporcionado por los minstrel shows se convirtió en la forma de entretenimiento más ampliamente difundida y en el producto comercialmente más exitoso de la Norteamérica del siglo XIX (Johnson, 2012a). Tal fue su impacto, que Derek B. Scott (2012) sugiere que la revolución de la música popular debería enmarcarse ya en el periodo decimonónico, pues entonces comenzaron a proliferar estilos populares en las grandes metrópolis como Viena, Londres, París y Nueva York con la polka, el music hall, la operetta, el cabaret y, también, el blackface minstrelsy.

Por lo que respecta al género de "la cara ennegrecida", fue en este momento en que se produjo esta notoria agitación cultural que se tradujo en una fisura con el arte de "alta cultura”. Además, su fama y popularidad traspasó tanto fronteras como océanos, y se instaló de forma exitosa en países como Reino Unido, Australia e incluso llegó a Sudáfrica (Waterhouse, 1985).

A partir de la década de 1840, en Reino Unido se asentó un gran número de compañías, las que actuaban constantemente en las principales ciudades del país, como Londres, Manchester o Liverpool, y ya para fines de 1850 había al menos cincuenta conjuntos ofreciendo sus servicios (Davis 2013; Waterhouse 1985: 3). Asimismo, ciudades como Londres se convirtieron en centros de producción y difusión de partituras para ser ejecutadas en los minstrel shows (Scott 2012: 155-156).

No obstante, esta "primera norteamericanización de la cultura popular" no tuvo gran impacto dentro de los centros musicales latinoamericanos, pues si bien es innegable que se produjo una cierta circulación de estas representaciones artísticas en los principales teatros hispanoamericanos del siglo XIX, su incursión en estos territorios fue escaso y no se instalaron compañías de forma permanente.

Para el caso chileno, tras analizar El Mercurio de Valparaíso y El Ferrocarril entre 1859 y 1860 , sostenemos que la primera llegada documentada del blackface fue realizada por los 
Ethiopian Minstrels, quienes entre septiembre y octubre de 1860 realizaron ocho conciertos en las ciudades de Valparaíso y Santiago ${ }^{15}$.

Estos artistas fueron presentados como los "Cantores Africanos 16 " en los medios locales, y así como anunció el periódico El Ferrocarril, esta compañía se habría fundado en 1854 en la ciudad de San Francisco. Después, tras obtener gran éxito en California y Nueva York, fue proclamada como la "más completa e individualmente como artistas sin rival en sus respectivos caracteres ${ }^{17}$ ". Sus integrantes, así como su tipo de voz o los instrumentos que interpretaban eran (ver Tabla 1):

TABLA 1: ARTISTAS, JUNTO CON SU ROL E INSTRUMENTOS ${ }^{18}$

\begin{tabular}{|c|c|}
\hline Artistas & Instrumentos, voces y roles \\
\hline D. J. Murphy & "Cómico africano" y falsete, castañetas [huesos] \\
\hline C. Henry & Primer tenor, guitarra y compositor \\
\hline W. H. Smith & Banjo, melófono. \\
\hline G. H. Edmonds & Violinista, director de orquesta \\
\hline J. Sterling & Flautista \\
\hline W. D. Corrister & Segundo tenor \\
\hline J. Wallace & Tambor (pandereta) y banjo \\
\hline G. W. Johnson & Director de escena \\
\hline
\end{tabular}

Fuente: Elaboración propia.

Observamos, por una parte, la presencia de la instrumentación básica de la primera etapa de los minstrel shows, como el banjo, el violín, la pandereta y los huesos ${ }^{19}$, los que se asociaban con la "música de la plantación", y es cierto que diversas evidencias muestran

15 Comenzamos a pesquisar la prensa desde 1859, porque la primera versión entregada por Pereira Salas la reseña como la fecha de llegada a Valparaíso. No obstante, no existe referencia alguna de esta compañía durante ese año. En el próximo apartado abordamos detalladamente cuándo aparecen y el tipo de representación que ejecutan en las ciudades de Valparaíso y Santiago. Además, si bien esta investigación todavía se encuentra abierta, por el diario El Comercio de Lima sabemos que actuaron en las ciudades de Callao y Lima durante diciembre de 1860. También, la edición de la tarde del 24 de diciembre de 1860 indica que su siguiente destino fue Guayaquil, en Ecuador.

16 Generalmente, junto con el nombre en castellano, también aparece su nombre en inglés entre paréntesis, (Ethiopian Minstrels).

17 Anuncio de actuación. El Ferrocarril, V/1488 (13 de octubre, 1860), p.3

18 Junto con estos artistas, viajaba también el empresario W.G. Smith. Programa de los Cantores Africanos, Teatro Municipal. 13, 17 y 28 de octubre de 1860.

19 Los huesos generalmente eran creados de fragmentos de costillas de vaca. Se usaban dos pares, uno en cada mano y se percutían sosteniéndolos entre los dedos, mediante un movimiento rápido de muñeca. Los buenos ejecutantes podían mostrar una gran complejidad rítmica. 
que estos instrumentos estaban ampliamente expandidos en esos lugares ${ }^{20}$. Con el paso del tiempo, y debido a que se fueron presentando composiciones más elaboradas, se incorporaron otros nuevos. Por ello, encontramos la guitarra, $u$ otros que se asocian a marchas militares como el melófono o la flauta, la cual podría hacer referencia al pífano.

Hay que mencionar, además, que el programa presenta a G. Johnson como el "director de escena", lo que nos hace suponer que se trata de la figura del "interlocutor", quien en un formato clásico cumple con un rol fundamental dentro de la estructura de esta forma de entretenimiento popular.

El interlocutor, único personaje que no se caracterizaba como afronorteamericano, era el maestro de ceremonias, pues presentaba y finalizaba cada gran acto. Mostraba, además, un buen uso del idioma y actuaba como lo haría un aristócrata, mientras que, a su vez, controlaba e interrogaba humorísticamente a los personajes "esquineros", como Tambo y Bones. Estos eran dos figuras también características del show, quienes recibían el nombre debido a los instrumentos que tocaban y se situaban en los dos extremos del semicírculo (Toll 1977: 52-53) (ver Figura 2). Podemos observar también la práctica colonialista de representar la necesidad de que un "hombre blanco", culto y de buena apariencia, controle de forma paternalista los buenos modales y la conducta de los "personajes negros".

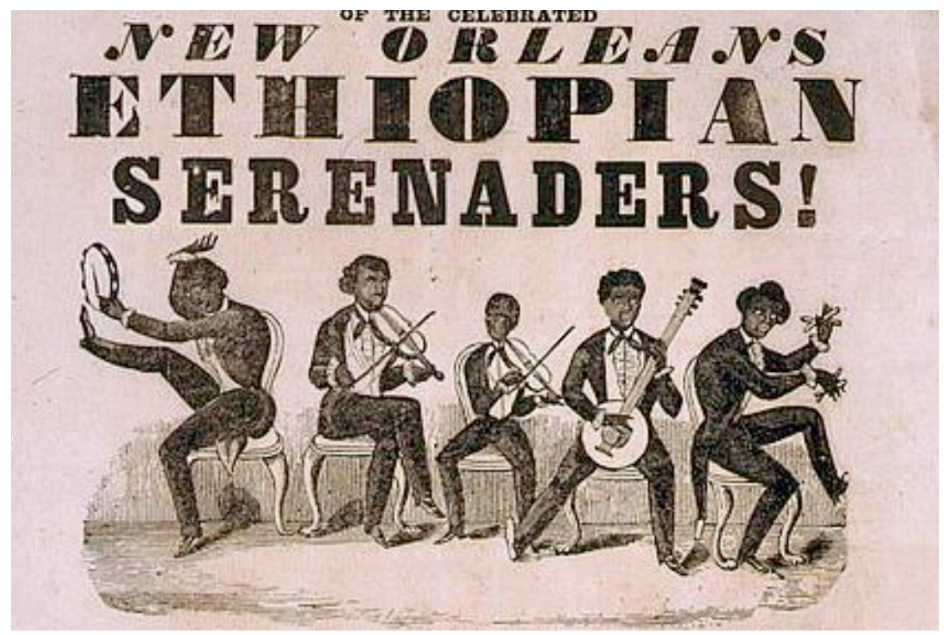

Figura 2: Anuncio de la actuación de los New Orleans Ethiopian Serenaders, 1847.

Ejemplo donde se muestra a Tambo y Bones sentados en las esquinas.

Fuente: Bellini, V., Maddox, J. M. \& New Orleans Ethiopian Serenaders. (1847) Fourteenth appearance in this country of the celebrated New Orleans Ethiopian Serenaders, 1847 [Estados Unidos] [Fotografía] Recuperada de: Library of Congress, https://www.loc.gov/item/2014635580/. [acceso: 19 de mayo, 2021]

20 Además de testimonios como los de Solomon Northup (1859), mencionamos el trabajo realizado por el Proyecto Federal, Born in Slavery: Slave Narratives from the Federal Writers' Project. En él, entre 1936 y 1938 se registraron más de 2.300 testimonios de antiguas personas esclavizadas a lo largo de diecisiete estados. Aquí aparece mucha información acerca del contexto y de las funciones de su música durante el periodo final de dicha institución. 
Por último, el análisis de prensa nos da luz acerca de las sospechas que nos suscitó la primera información entregada por Eugenio Pereira Salas, quien aseguró que esta compañía "negra" estadounidense interpretó spirituals. En primer lugar, la denominación de "Cantores Africanos" nos remitiría a un origen desde alguna parte de ese extenso continente, pero, además, en ocasiones las crónicas locales apuntan a esa misma dirección. Para ser más específicos, tras observar las dos primeras actuaciones de esta compañía, El Mercurio de Valparaíso publicó, el lunes 10 de septiembre de 1860, una crítica de la actuación donde enfatiza: "Ha habido escenas, es verdad, que hubiéramos deseado ver suprimidas, si ellas no tuvieran alguna novedad y no fueran acaso parte de las costumbres de los negros africanos ${ }^{21}$ ".

Más aún, el 1 de octubre, este mismo medio presentó una última nota de forma mucho más benevolente: "La función dada el sábado a beneficio de los Sres. Murphy y Henry fue regularmente concurrida y los asistentes parecieron gustar por última vez de los cantos africanos 22 ". Vemos, entonces, que en ocasiones se asocia de manera un tanto difusa las características culturales y los valores de esta compañía dentro de un imaginario que lo conecta con ese continente.

Ahora bien, así como sostiene Legnini (2011: 52), durante el siglo XIX el descriptor ethiopian se utilizó para denotar todo lo que tuviera que ver con "lo africano", tanto en Estados Unidos como en Reino Unido. En este sentido, mediante el nombre Ethiopian Minstrels se buscaba lograr una mayor recepción del público, al asociarse con elementos prístinos y desconocidos. Evidentemente, este grupo teatral utilizó la misma fórmula para presentarse ante un público hispanohablante, y para ello debieron traducir el nombre de la compañía. Sin embargo, para ganar notoriedad, vimos que se publicitaron como un conjunto norteamericano que había obtenido grandes alabanzas en las principales ciudades del país. Igualmente, elementos como el idioma o su interpretación artística, como veremos, los conectaba con el "Profundo Sur" de Estados Unidos.

Hay que mencionar, además, que leyendo con atención se nos presenta la verdadera estética de sus integrantes. El 10 de septiembre, una crónica local publicada por El Mercurio de Valparaíso advierte al espectador porteño que, de haber salido decepcionado del espectáculo realizado por los "Cantores Africanos", fue debido a que no tomó en consideración cuál era su "naturaleza":

No dudamos que algunos de delicado gusto habrán salido del teatro sufriendo una decepción; mas habrá sido tal vez porque no se propusieron entrar con el propósito de encontrarse con negros en escena, o mas claro, con personajes que tratan de representar las costumbres de una raza abyecta ${ }^{23}$.

Admitamos por el momento que la aclaración referente a "personajes que tratan de representar las costumbres de una raza abyecta”, más allá de demostrar abiertamente sesgos y prejuicios raciales en contra de la población afroamericana, también alude a que, en realidad, se trata de personas que se han caracterizado como tales, y que estarían realizando una representación sobre el escenario. Pero, si bien podríamos albergar alguna duda, posteriormente el mismo medio se muestra mucho menos ambiguo cuando, el primero de octubre, asevera: "Se prodigaron aplausos a los simulados negros, y estos habrán quedado satisfechos de la acojida que han merecido sus espectáculos²" (ver Figura 3).

21 Crónica local, El Mercurio de Valparaíso, XXXIII/9908 (10 de septiembre, 1860), p. 3.

22 Crónica local, El Mercurio de Valparaíso, XXXIII/9923 (1 de octubre, 1860), p. 3

23 Crónica local, El Mercurio de Valparaíso, XXXIII/9908 (10 de septiembre, 1860), p. 3.

24 Crónica local, El Mercurio de Valparaíso, XXXIII/9923 (1 de octubre, 1860), p. 3. 


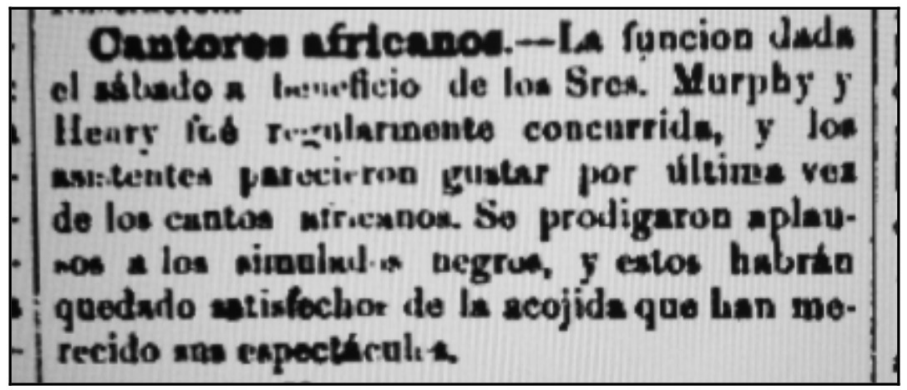

Figura 3: Crónica local aparecida en El Mercurio de Valparaíso, 1 de octubre, 1860. Fuente: Crónica Local, "Cantores Africanos,- La función dada el sábado...", El Mercurio de Valparaíso, XXXIII/9923 (1 de octubre, 1860), p. 3.

Sostenemos entonces que las representaciones llevadas a cabo por los Ethiopian Minstrels, como sugerimos ya en las consideraciones iniciales, corresponden a un blackface minstrelsy. A continuación, abordaremos cómo y cuándo fue su llegada, analizaremos los roles de los diferentes artistas que integraban la compañía, su número de actuaciones y cuál fue el repertorio que presentaron ante la audiencia en Chile.

\section{LA GRAN FUNCIÓN, "VOCAL, INSTRUMENTAL Y BAILE" DE LOS "CANTORES AFRICANOS"}

El primer anuncio que hace referencia a la llegada de esta compañía aparece recogido en El Mercurio de Valparaíso el miércoles 5 de septiembre de $1860^{25}$ y, curiosamente, menciona únicamente la actuación de un "concierto vocal e instrumental de la Compañía NorteAmericana" para el Teatro de la Victoria de esta ciudad. Así, un conjunto representado por ocho artistas ofrecía un "entretenimiento enteramente nuevo en el país" para los días 8 y 9 de septiembre, con un número que contaba con "canciones, coros, baladas, solos, dúos, tríos, burlescos, etc., etc" 26 .

Unos días más tarde, sí aparecieron catalogados bajo el nombre de los "Cantores Africanos", concretamente en el anuncio publicado en El Mercurio de Valparaíso el 12 de septiembre ${ }^{27}$, en el que se comunicaba la tercera y última función de la compañía a realizarse el día siguiente. Después de esta actuación, efectuaron dos presentaciones más, los días 22 y 29 del mismo mes, lo que nos lleva a pensar que obtuvieron un beneficio inicial lo suficientemente alto como para aumentar su número de actuaciones en la ciudad antes de partir hacia Santiago.

También, las crónicas publicadas muestran que esta compañía ganó las simpatías de la sociedad extranjera que residía en la ciudad portuaria y, por ello, extendieron sus funciones. Y es que su último concierto se realizó "por instancia de muchos extranjeros 28 " a la empresa del teatro, hecho que produjo que su último acto se organizara a beneficio de sus artistas.

25 Del mismo modo se anunció los días 6, 7 y 8 del mismo mes.

26 Anuncio de actuación, El Mercurio de Valparaíso, XXXIII/9904 (5 de septiembre, 1860), p. 3.

27 Anuncio de actuación, El Mercurio de Valparaíso, XXXIII/9910 (12 de septiembre, 1860), p. 3.

28 Crónica local. El Mercurio de Valparaíso, XXXIII/9921 (28 de septiembre, 1860), p. 3 
En relación con esto último, hay que considerar que, después de su independencia, Chile favoreció una política económica de apertura con las principales casas comerciales extranjeras. Debido a esto, durante el siglo XIX Valparaíso se convirtió en el principal eje económico del país, pues su puerto era clave para articular las rutas de comunicación entre Europa y la costa del Océano Pacífico ${ }^{29}$ (Sánchez, Bosque y Jiménez 2009; Couyoumdjian 2000).

En este contexto, se estimuló la llegada de inmigración de carácter comercial y de profesiones liberales, destacando aquellos de nacionalidad británica; para la primera mitad del siglo XIX, entre población flotante y los que se radicaron en el país, su número oscilaba entre las 1000 y 3000 personas (Pinochet 2012; Sánchez, Bosque y Jiménez 2009). No obstante, si bien la nacionalidad británica y sus casas comerciales destacaron por sobre el resto, también fueron importantes la alemana, francesa, italiana y estadounidense.

Evidentemente, ello no repercutió solamente en lo económico, pues la elevada migración británica en suelo porteño impulsó la creación de colectividades e instituciones para preservar su cohesión y tradiciones, fundando colegios e incluso periódicos en lengua inglesa (Pinochet 2012; Sánchez, Bosque y Jiménez 2009) ${ }^{30}$. Este protagonismo se percibió también en el ámbito cultural, y como sucede en este caso, muchos espectáculos se presentaban previamente en Valparaíso antes que en la capital (Piña 2009: 23). Es de suponer, entonces, que la llegada de la compañía teatral norteamericana atrajo un especial interés de aquella "sociedad extranjera" de habla inglesa que residía en la ciudad.

Posteriormente, ya en Santiago, fueron anunciados en El Ferrocarril como los mejores artistas del día, pues habían alcanzado gran renombre y "entusiastas aplausos y pruebas de afecto" debido a un repertorio que contaba con "canciones, baladas, burlescas, etc." ${ }^{1}$. Y así los Ethiopian Minstrels realizaron tres conciertos los días 13, 17 y 28 de octubre en el Teatro Municipal (ver Tabla 2 y Figura 4 ).

\section{TABLA 2: CONCIERTOS REALIZADOS EN CHILE POR LOS “CANTORES AFRICANOS” (ETHIOPIAN MINSTRELS) EN 1860}

\begin{tabular}{|c|c|}
\hline Ciudad & Fecha \\
\hline Valparaíso & Septiembre: $8,9,13,22$ y 29 \\
\hline Santiago de Chile & Octubre: 13,17 y 28 \\
\hline
\end{tabular}

Fuente: Elaboración propia.

29 Esto explica que a lo largo del siglo XIX y hasta mediados del XX, en la ciudad se produjo el surgimiento de bancos, sedes y sociedades industriales y mineras, así como compañías navales y exportadoras, que consiguieron aglutinar buena parte de las transacciones monetarias del país (Sánchez et al. 2009: 270-277).

30 Este impacto modificó incluso el paisaje de la ciudad, pues a lo largo de este siglo se construyeron numerosas casas al estilo victoriano, especialmente en Cerro Alegre, que "transformaron en un área tan típicamente británica que equivalía a una colonia inmersa en el puerto” (Méndez 1987; 167).

31 Anuncio de actuación. El Ferrocarril, V/1488 (13 de octubre, 1860), p.3. El mismo anuncio apareció en los números del 16, 17, 25, 26 y 27 de octubre. Estos últimos tres días, sin embargo, lo hizo junto con una imagen de la compañía sentada en semicírculo (ver Figura 4). 


\section{TEA'TRO MUNICIPAL.}

GRAN FUNCION

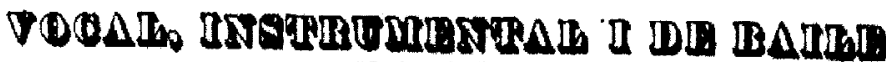 of Los ufinuns}

cangropias anducatos

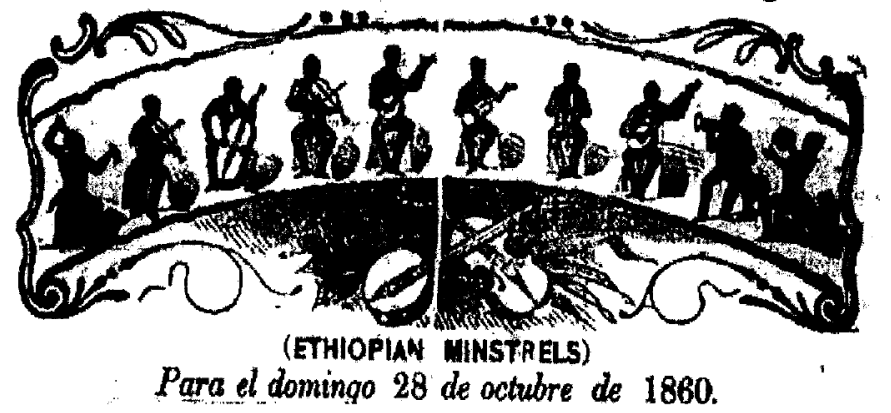

Figura 4: Portada del anuncio publicado en El Ferrocarril, el 25, 26 y 27 de octubre de 1860. Fuente: El Ferrocarril, V/1498, p. 3

Las actuaciones estuvieron divididas en su formato clásico de tres secciones. En su primera parte, la compañía presentó un espectáculo variado en el que se combinaron óperas burlesques $^{32}$, canciones cómicas y conjuntos corales, así como baladas y una marcha militar.

Para ser más específicos, los "Cantores Africanos" realizaron su "Gran Obertura", representando la famosa ópera cómica Fra Diavolo, del compositor francés Daniel Auber, la cual era "interpretada por toda la compañía 33 ". Pero, como es lógico, dentro de su repertorio también aparecen composiciones cómicas destinadas a ser representadas por el minstrel show, como por ejemplo "Camptown Races"34 de Stephen Foster. Mediante su escucha, realizada durante el primer acto del 17 de octubre en el Teatro Municipal, el público pudo acercarse a tópicos asociados con lo "afro", como lo es el canto responsorial o la sincopación 35 (ver Figura 5).

32 El burlesque fue un género dramático donde se ridiculizaba un tema, una representación o estilo musical que fue muy popular en los teatros de variedades de época victoriana. Estas óperas burlesques, asimismo, obtuvieron un gran éxito durante el siglo XIX norteamericano, en un momento donde la "ópera seria" no estaba triunfando. Así, "la alta cultura" era subvertida bajo los valores y la estética de la cultura popular (Winans 1996: 160-161).

33 Programa de los Cantores Africanos, Teatro Municipal. 13 de octubre de 1860.

34 Programa de los Cantores Africanos, Teatro Municipal. 17 de octubre de 1860.

35 La sincopación, como sugiere Derek B. Scott (2012: 150-151), es un elemento que también aparece en músicas europeas de la zona del mediterráneo. No obstante, un gran número de composiciones realizadas por Foster o por Daniel Emmet se realizaron usando estos ritmos, pues así se mostraba el "carácter negro" de la obra. Asimismo, este autor defiende que la "síncopa afroamericana" no se acentuaba, al contrario de aquella realizada en Europa. 

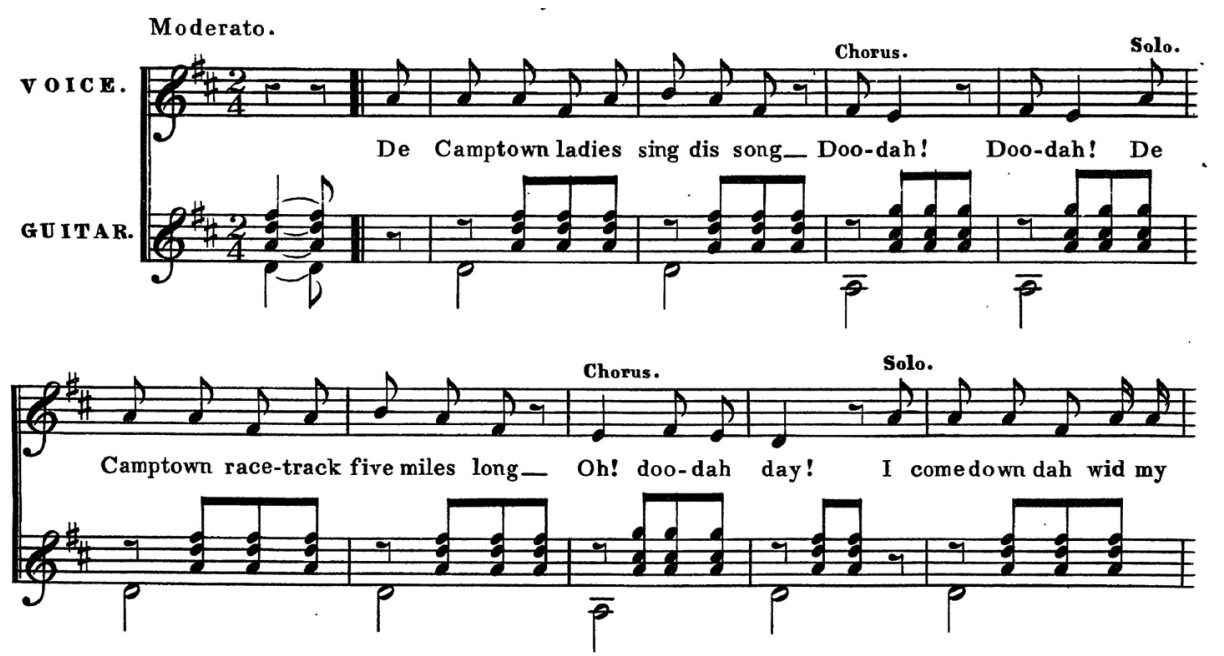

Figura 5: "Camptown Races", compuesta por Stephen Foster (Baltimore: Benteen, 1850).

Observamos el canto responsorial entre el Chorus y la parte solista, así como su sincopación. Fuente: Recuperada de: Library of Congress, https://www.loc.gov/item/sm1852.191670/

[acceso: 19 de mayo, 2021]

Durante el primer acto, no obstante, destacaron las baladas de tradición inglesa y escocesa, las que fueron interpretadas por los tenores C. Henry y W.D. Corrister. Estas "canciones sentimentales", definidas así en los programas, versaron acerca del amor o del luto que supone la pérdida de los seres queridos que han sido separados forzadamente debido a la esclavitud, como en "Lost Child" 36 o "Nelly Grey" 37 . Aparece también otro tema recurrente dentro de las baladas ejecutadas en los minstrel shows: el tópico que gira en torno a la figura de la madre, como en "Mother Dear, I am thinking on the thee" 38 , que en una primera instancia fue catalogada erróneamente como spiritual por Eugenio Pereira Salas (1948: 68).

Otra de las canciones que etiquetó como spiritual fue "Black Smoke Rising”, la que, si bien no hemos podido individualizar, en el programa aparece descrita como "Coro y Solo cómico 39", y cuya parte solista fue interpretada por el "cómico africano" D. J. Murphy. Por tanto, esta mención de obra satírica nos hace descartar que se trate de un spiritual, debido a que estos tenían un carácter profundamente solemne y religioso.

En la segunda parte del show, una vez abierto el telón, el público chileno se transportó hacia alguna plantación situada en los lejanos estados del sur de Norteamérica, bajo el epíteto: "Escenas en los plantíos después de un día de fiesta". Este carácter original es destacado en los programas impresos, porque las piezas musicales eran ejecutadas con "el banjo: instrumento peculiar de los negros", o incluían también números como "solo con huesos", "solo con violín" o con bailes humorísticos que eran "característicos de negros". de 1860

36 Programa de los Cantores Africanos, Teatro Municipal. Interpretada los días 13 y 17 de octubre

37 Programa de los Cantores Africanos, Teatro Municipal. 28 de octubre de 1860. de 1860

38 Programa de los Cantores Africanos, Teatro Municipal. Interpretada los días 13 y 17 de octubre

39 Esta obra fue interpretada durante las tres funciones llevadas a cabo en la ciudad de Santiago. 
Estas representaciones se intercalaron con más baladas, alguna polca, danzas cómicas y marchas militares en las que los personajes aparecerían caracterizados con uniformes del ejército y de la marina.

En el tercer acto, todavía dentro de la plantación, siguieron representando "Canciones, bailes y escenas de los esclavos en los plantíos". Esta sección, después de presentar dúos de banjo, finalizaba con una conocida pieza realizada por toda la compañía, como por ejemplo, "Old Bob Ridley" 40 , donde también encontramos el satirizado dialecto de los afroamericanos del sur, así como el tópico de canto responsorial (ver Figura 6).

\section{Old Bob Ridley!}

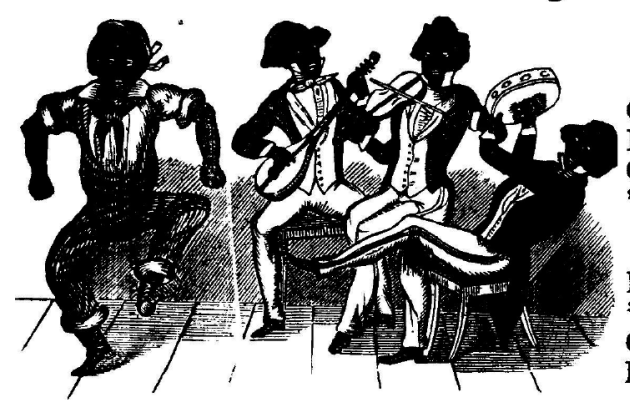

Now white rolks I'll sing you a ditty,

I'se trom home but dat's no pity,

$\mathrm{Oh}$, to praise myself it am a shame,

But Robert Ridley is ny name.

Oh Bob Ridley ho, Oh Bob Ridley ho, Oh Bób Ridley! Oh!! Oh!!!

ROBERT RIDLEY, HO !
Oh, white folks I hab cross'd de mountains,

How many miles I did'nt count 'em,

$\mathrm{Oh}$, I'se left de folks at de old Plantation,

'An come down here for my education.

Oh, Bob Ridley, ho. \&c.

De first time dat I eber got a lickm,

'Was down at de forks ob de cotton pickin,

0 , it made me dance, it made me tremble,

I golly it made my eye-balls jingle.

Oh, Bob Ridley, ho, \&c.

Philadelphia am a mighty fine city,

For beauty and location it ain't behind 'em,

Oh, de ladies all look so sweet and gidley,

Wonder dey don't fall in love wid old Bob Ridley.

Oh Bob Ridley, ho, \&c.

Figura 6: Old Bob Ridley. American Song Sheets. Fuente: Old Bob Ridley. Johnson's, No. 5 North Tenth St. Phila. Monographic. Recuperado de: Library of Congress, https:/ /www.loc.gov/item/ amss.cw104110/ [acceso: 19 de mayo, 2021]

Si bien este esquema general se mantuvo durante todos los conciertos que representaron en suelo santiaguino, vemos que variaron ligeramente de repertorio en cada una de las secciones del espectáculo. El cambio drástico se produjo en su último número, realizado el 28 de octubre de 1860 en el Teatro Municipal, pues en la segunda parte aparecen menos piezas que tienen relación con los "instrumentos de plantación" y aumentan, por otra parte, el número de polcas y baladas. De igual manera, la última parte del acto cambió de escenografía, pues se reemplazó el escenario rural por uno urbano, en el que se representa una escena entre los barberos Tamboy Bones, es decir, por J. Wallace, quien toca la pandereta y D.J. Murphy, cuyas manos sostienen dos pares de huesos ${ }^{41}$.

40 Programa de los Cantores Africanos, Teatro Municipal. 13 de octubre de 1860.

41 Es interesante considerar aquí la posible relación e influencia que tuvieron estas representaciones en el barbershop music, un estilo vocal armónico, cantado a capella, generalmente por un grupo de cuatro integrantes de manera homófona. Suelen estar formados por dos tenores, uno de ellos ejerciendo de voz principal, un barítono y otro bajo. Si bien académicos observan influencias culturales cruzadas 
En un último apartado, y debido a que el contexto sociopolítico y cultural chileno difería notablemente del estadounidense, defenderemos que se produjeron alteraciones del repertorio clásico de esta forma de entretenimiento. Por último, argumentaremos que el minstrel show reforzó tanto el sentido de alteridad racial como confirmó una inferioridad estética, musical y moral de este género respecto de los hábitos musicales y teatrales a los que estaban acostumbrados, o que se estaban introduciendo entre la audiencia chilena en el siglo XIX.

\section{REPRESENTANDO LA DIFERENCIA}

El contexto y las condiciones para la recepción chilena del blackface minstrelsy diferían enormemente de su lugar de origen referencial en el sur de Estados Unidos, por razones culturales, sociales e históricas.

En efecto, la escenografía, la música, los bailes y los personajes allí representados aludían a una cultura lejana y todavía poco conocida, la de una Norteamérica que había sido colonizada por los británicos, y donde además se mostraba la pervivencia de una esclavitud que en Chile había sido abolida el 24 de julio de 1823. Por otra parte, si bien la influencia y presencia de población esclavizada y sus descendientes en Chile era mucho mayor de la que ocultó la narrativa canónica blanqueante del siglo XIX y mediados del XX (Cussen 2006; Domingo 2021), es cierto que estuvo lejos de los cuatro millones de personas esclavizadas que habitaban los estados de la Unión en 1861 (De la Guardia 2012: 183).

Además, la posible no comprensión del inglés marcó profundamente el devenir de este tipo de entretenimiento en suelo chileno, ya que una parte de su potencialidad giraba en torno a él por varias razones. Para empezar, uno de los elementos empleados para diferenciarse del afronorteamericano fue debido a su habla, y por ello se representó al esclavizado con un marcado y estereotipado dialecto. Es interesante observar cómo parte de los compositores lo reflejaron de manera explícita en la letra de las "canciones de plantación" (dey para they; hab para have; 'em para them...).

De este modo, el dialecto se convirtió en un fundamento que otorgaba autenticidad al espectáculo, pero también revela cómo parte de la sociedad estadounidense caracterizó la identidad "Otra", marcando al afrodescendiente como incapaz de hablar como aquel que ostenta el poder de la acción y de la palabra. Pero este hecho pudo no ser percibido por todo el público en suelo chileno.

Podemos afirmar que la elevada presencia de población inglesa y estadounidense en Valparaíso, como mencionamos, sí permitió que este segmento de auditores captara toda la amplitud del espectáculo. Además, a pesar de que las fuentes de prensa no mencionan el perfil de los asistentes al teatro, ni cuál fue la proporción de la sociedad migrante, observamos que fue lo suficientemente elevada e importante como para ejercer presión y lograr que aumentara el número previamente anunciado de espectáculos.

La realidad vivida en el Teatro Municipal debió ser distinta y, pese a que las fuentes de prensa tampoco mencionan el nivel socioeducativo de la audiencia allí congregada ${ }^{42}$,

(Averill 2003: 3-48), la presencia y el aporte afrodescendiente ha sido muy importante dentro de esta expresión artística (Abbott 1992). Asimismo, Averill (2003) destaca la influencia de las representaciones blackface minstrelsy como un antecedente que contribuyó en la difusión de este tipo de canto armónico.

42 Como señalan Ponce de León, Rengifo y San Martín (2010), en 1854 se realizó un Censo General en Chile para conocer el nivel de alfabetización de la población como base para construir el sistema de educación pública. Este estudio evidenció que la sociedad de mediados del siglo XIX era mayoritariamente analfabeta, pues "leían en Chile 12,8\% de la población total mayor de cinco años, 
varios elementos nos permiten sostener que, mayormente, no se comprendió el idioma inglés. Principalmente debido a que, analizando los programas representados en Santiago, observamos que se produjo una modificación respecto del repertorio clásico del blackface minstrelsy.

Primeramente, como señalamos con anterioridad, para evidenciar esta alteridad jugaba un rol importante la interacción de los artistas "del corcho quemado" con el interlocutor blanco que, como planteamos, dentro de los "Cantores Africanos" era personificado por G. Johnson. En este sentido, comprobamos que su figura no tiene prácticamente incidencia en los programas teatrales y, únicamente en su última función, realizada en el Teatro Municipal de Santiago el 28 de octubre de 1860, aparece un "discurso a la respetable audiencia”, realizado además por J. Murphy y no por Johnson. Lamentablemente, no aparece ninguna información que haga referencia al idioma en que se produjo, pues no se publicaron reacciones concretas de este hecho en la prensa.

Igualmente, otro aspecto capital dentro del show clásico eran los chistes, los acertijos lanzados hacia el público y los largos discursos. Por esta razón, observando su escasa presencia en las funciones llevadas a cabo en la capital, intuimos que estos artistas pudieron haber advertido la necesidad de eliminar de su repertorio los contenidos orales que exigían la comprensión del idioma para producir diversión.

Para mitigar este vacío, los Ethiopian Minstrels aumentaron la sección dancística, instrumental y cantada, pero aún con todo, se continuó restringiendo el significado real de este show. Observemos "Nelly Grey", una canción que presentaron en Chile. Esta obra, compuesta por Benjamin Hanby sin presencia de dialecto, está narrada en primera persona desde la perspectiva de una persona esclavizada que se lamenta trágicamente por la venta de su amada.

Oh! my poor Nelly Gray, they have taken you away, / Oh, mi pobre Nelly Gray, te han llevado And I'll never see my darling any more; / Nunca más veré a mi amor

I'm sitting by the river and I'm weeping all the day. /Estoy sentado junto al río y lloro todo el día For you've gone from the old Kentucky shore. /Porque te has ido de la vieja costa de Kentucky

Evidentemente, una adecuada comprensión del inglés podía suscitar entre el público sentimientos de empatía hacia su persona, provocando una visión crítica en contra del sistema esclavista. Pero también, aparte de valorar el cambio de repertorio y la escasa incidencia del interlocutor, otro indicio que nos impulsa a pensar en esta dirección es que la crítica de los diarios solo valoró la parte estética y musical de la actuación.

La parte cómica entonces, se ilustró mediante el comportamiento hiperactivo de los personajes negros, con bailes enérgicos y movimientos eléctricos, mientras tocaban sus

un $15,2 \%$ entre los hombres y un $10,4 \%$ entre las mujeres. Escribían un $13,5 \%$ de los hombres y un 7,8\% de las mujeres" (Ponce de León, Rengifo y San Martín 2010: 306). La realidad de las ciudades de Valparaíso y Santiago, si bien se mantenían por encima de la media nacional, continuaban siendo bajas, pues contaban "con una población alfabeta de un 23,1\% y un 18,2\%, respectivamente" (306). Pese a ello, desde inicios del siglo XIX, "el arte dramático se transformó en uno de los espectáculos preferentes de los grupos letrados” (Donoso y Huidobro 2015: 80). Debemos considerar también, que el Teatro Municipal estaba localizado en "el corazón de la zona más pudiente" de la ciudad, y definía las características socioeconómicas de sus habitantes (Piña 2009: 69). Durante el último tercio del periodo decimonónico, comenzó a consolidarse un teatro y un circuito cultural crítico abocado a las clases populares y sensible a las demandas sociales. No obstante, el elevado costo del arriendo de salas de prestigio como el Municipal conllevaba que se realizaran en circuitos alternativos (Donoso 2017; Donoso y Huidobro 2015). 
instrumentos y se estremecían entre gritos y risas. También encontramos efectos de sonidos e imitaciones cómicas, como la "imitación del ferrocarril" 43 , realizada por Murphy. Y fue justo la parte de la comedia basada en los movimientos físicos y aquellas escenas desarrolladas en la plantación la que generó una mayor crítica negativa en las crónicas de los diarios.

Vemos cómo El Mercurio de Valparaíso asoció este comportamiento debido a las "costumbres mas sencillas, de vida mas naturalota $[s i c] \ldots$ de los negros en escena" ${ }^{4}$. En otra actuación, si bien reconocían el mérito de su presentación, recomendaron a la compañía la supresión de las "escenas grotescas y de mal gusto45". Más evidente se mostró el cronista del 24 de septiembre, cuando argumenta:

Sus escenas grotescas hicieron reir... pero qué sandez no escita a ello! Si van con su música a otra parte, bien recibidos serán, no lo dudamos, pero hagan lo posible por economizar esos que ni son sainetes ni entremeses, y a que ellos dan el título de Escenas en los plantíos ${ }^{46}$.

Esta alusión directa a representaciones teatrales propias del género chico, como lo es el sainete, es especialmente reveladora para entender el punto de referencia desde donde se juzgó al blackface minstrelsy.

Como breve antecedente, es importante considerar que, a lo largo del siglo XIX en Chile, la ópera se erigió como el espectáculo que dominó el panorama social y cultural de la oligarquía y de las clases más acomodadas, la que era ejecutada mayoritariamente por compañías líricas italianas que arribaban al continente (Piña 2009; Donoso y Huidobro 2015). No obstante, desde la segunda mitad del siglo XIX, la zarzuela comenzó a ganar gran popularidad y afectos entre la población. Este género musical escénico español, de carácter costumbrista, y que contiene partes instrumentales, vocales y habladas, era generalmente interpretado por compañías españolas mientras estaban de gira en Latinoamérica (Piña 2009).

Conjuntamente y de forma paralela a esta representación, al país llegó el "género chico", como el sainete, y cuya principal diferencia es que únicamente tiene un acto y su carácter es más simple que la trama argumental de la zarzuela. Progresivamente fueron conformándose diversas compañías que presentaban estos géneros de forma masiva, favorecido además por la proliferación de funciones por tandas (Piña 2009).

Teniendo esto en consideración, la comparación implícita que la crónica local ejerce entre el blackface minstrelsy y el sainete puede deberse a que este último también lleva a escena elementos de raigambre popular, por medio de la representación de sus personajes y por el lenguaje utilizado. A pesar de ello, difiere notablemente en la realidad mostrada, pues el sainete no cae en lo burdo, sino que alude a escenas costumbristas y a la vida popular española (Piña 2009).

A su vez, postulamos que la comparación con el entremés puede ser debido a que, tal como afirma Piña, "este tipo de entretenimiento en clave de comedia [...] combina elementos del ballet, acrobacia, pantomima, etc.” (Piña 2009: 91). Yjustamente, aunque su temática e intencionalidad difiere ostensiblemente, los comediantes de la cara ennegrecida también llevaban este tipo de diversión y espectáculo a su escenario.

En definitiva, debido a los hábitos teatrales de la época, y a juzgar por los comentarios realizados en la prensa, observamos cómo se asoció la falta de moderación física y moral

43 Programa de los Cantores Africanos, Teatro Municipal. 28 de octubre de 1860.

44 Crónica Local, El Mercurio de Valparaíso, XXXIII/9908 (10 de septiembre, 1860), p. 3

45 Crónica Local, El Mercurio de Valparaíso, XXXIII/9912 (14 de septiembre, 1860), p. 3

46 Crónica Local, El Mercurio de Valparaíso, XXXIII/9917 (24 de septiembre, 1860), p. 3 
de los personajes del blackface minstrelsy con características y costumbres preconcebidas que el público chileno ligó con la "raza negra". Asimismo, debemos tener presente que, a mediados de siglo, parte de la dramaturgia nacional se abocó a generar conciencia de la vida republicana, como base para el progreso y orden social (Donoso y Huidobro 2015: 80). Este hecho también chocaba con los ejemplos cívicos allí representados.

En contraste, entonces, esta actuación sirvió para afirmar la superioridad estética, musical y moral de los géneros escénicos que el público nacional estaba consumiendo. En esta línea, otro argumento para restarle valor al minstrel show fue su poca complejidad musical y orquestal. Por esto El Mercurio de Valparaíso recomendó a sus lectores: "La compañía de Cantores Africanos no es para sostener temporadas con sus funciones, pero sí podrá presentarse ante un público para distraerlo por algunas noches y ser objeto de curiosidad ${ }^{47}$ ".

Similarmente, el nivel artístico no permitía su exposición prolongada debido a la limitada variedad de su instrumentación, "el público se daría por satisfecho con la parte buena de la función, aunque no podría dejar de notar la falta de orquesta, con la que tan acostumbrados estamos y cuya ausencia hace que el teatro presente un aspecto un tanto triste ${ }^{48}$ ". Como consecuencia, los "Cantores Africanos" presentaron un repertorio que fue percibido por la audiencia chilena como repetitivo y uniforme, "no ofrecieron novedad alguna; su música y canto, si no idénticas a las anteriores, fueron por el mismo estilo" 49 . En todo caso, la prensa destacó el carácter novedoso del minstrel show en Chile, además de reconocer una cierta virtud en la parte musical debido al nivel de ejecución instrumental: "examinando a cada uno de los artistas y sus instrumentos, no habrá podido menos que reconocerse el mérito relativo de su maestría y gran destreza en la ejecución” 50 .

Dentro del repertorio, asimismo, los críticos destacaron la parte vocal, principalmente las baladas, que fueron interpretadas por los dos tenores de la compañía: "el público ha aplaudido las partes de canto, sobre todo en las que el tenor M. Henry podía lucir su voz" A causa de su especial habilidad y destreza, entonces, se puede entender por qué la última actuación que esta compañía realizó en Valparaíso fue promovida para "hacer una manifestación de simpatías a dos de los principales artistas de la compañía. Bien lo merecen" 52.

Por último, la idea reflejada por la prensa que relaciona la originalidad de la actuación con la curiosidad que provoca en la audiencia se repite en gran parte de los comentarios tras sus representaciones, aunque tampoco recibieron, como vimos, una respuesta unánime y entusiasta.

\section{CONSIDERACIONES FINALES}

Ahora podemos decir que la primera vez que la audiencia chilena creyó observar las prácticas culturales afronorteamericanas, lo hizo en las funciones de la compañía blackface de los Ethiopian Minstrels. Por esta razón, mediante el análisis de la actuación realizada por esta compañía y su recepción, sostenemos que ayudaron a la audiencia allí reunida a identificarse positivamente como blancos, pues se estableció una referencialidad y un imaginario racial superior, tanto en la parte estética -es decir, por la complejidad musical

47 Crónica Local, El Mercurio de Valparaíso, XXXIII/9908 (10 de septiembre, 1860), p. 3

48 Crónica Local, El Mercurio de Valparaíso, XXXIII/9912 (14 de septiembre, 1860), p. 3

49 Crónica Local, El Mercurio de Valparaíso, XXXIII/9917 (24 de septiembre, 1860), p. 3.

50 Crónica Local, El Mercurio de Valparaíso, XXXIII/9908 (10 de septiembre, 1860), p. 3.

51 Crónica Local, El Mercurio de Valparaíso, XXXIII/9908 (10 de septiembre, 1860), p. 3.

52 Crónica Local, El Mercurio de Valparaíso, XXXIII/9921 (28 de septiembre, 1860), p. 3. 
y orquestal a la que estaban habituados- así como por las nociones que este espectáculo asociaba con la cultura negra.

$\mathrm{Y}$ es que estos personajes representaron papeles donde se destacaba la ignorancia, la falta de moderación y el descontrol corporal. Estas asociaciones, evidentemente, también se produjeron debido a ideas preconcebidas que estaban ya instaladas en el imaginario colectivo de los asistentes al teatro, y ayudaron a seguir perpetuando estereotipos y caricaturizaciones que nada tenían que ver con la realidad de la afrodescendencia estadounidense. Esta representación artística, entonces, provocó una racialización negativa del espacio sonoro y de la corporalidad del afronorteamericano que, pese a que no tuvo éxito en Chile y no se instaló como forma de entretenimiento popular, colaboró en sumar connotaciones acumuladas previas que ya estaban naturalizadas.

Esto es debido a que tanto la música como las prácticas culturales y artísticas son medios constitutivos de la vida social, pues son percibidos junto con valores, ideas, imágenes y relaciones sociales que van más allá del arte, y que entran dentro del campo de la representación, de la vida social y de las identidades colectivas (DeNora 2004). Ideas que, controladas y difundidas por la sociedad dominante, fijaron y encorsetaron a una parte de población que en ese momento todavía no disponía de tanta capacidad de agencia y contestación.

Como mencionamos, si bien hoy podemos encontrar trabajos que relacionan a esta compañía con música afronorteamericana, específicamente el caso de los spirituals (Menanteau 2006: 25-26), no fue sino a partir de la década de 1870, cuando los Fisk Jubilee Singers, un conjunto afroamericano muy alejado de los parámetros del blackface, dieron a conocer un nuevo tipo de canción popular religiosa que revolucionó tanto los corazones como las salas de conciertos en distintos puntos del mapa (Graham 2018).

Paradójicamente, cuando se conocieron los verdaderos spirituals realizados por la población afroamericana de EE.UU., resultaron ser una expresión totalmente opuesta a los estereotipos utilizados para definirlos. Estas canciones de dolor (sorrow songs), nombradas así por W. E. B. Du Bois (2007: 168-169) ${ }^{53}$, fueron "el mensaje articulado del esclavo al mundo" 54 , un mensaje por tanto tiempo incomprendido y confundido por sus conciudadanos, que resultó ser "el mayor regalo del pueblo negro" 55 .

\section{BIBLIOGRAFÍA}

Аввотт, LyNn

1992 “"Play That Barber Shop Chord”, American Music, X/3, pp. 289-325. doi:10.2307/3051597

Allen William F., Lucy M. Garrison y Charles P. Ware

1867 Slave Songs of the United States. Nueva York: A. Simpson \& Co.

Averill, Gage

2003 Four parts, no waiting: A Social History of American Barbershop Harmony. Nueva York: Oxford University Press.

BRADFORD, SARAH

1886 Harriet Tubman: The Moses of Her People. Nueva York: Geo. R. Lockwood \& Son.

53 La primera edición es de 1903.

54 The articulate message of the slave to the world (la traducción es nuestra).

55 The greatest gift of the Negro people (la traducción es nuestra). 
BROWN, LEE B.

2013 "Can american popular vocal music escape the legacy of blackface minstrelsy?”, Journal of Aesthetics and Art Criticism, LXXI/1 (invierno), pp. 91-100. doi: $10.1111 / \mathrm{j} .1540-6245.2012 .01545 . \mathrm{x}$

Cockrell, Dale

2012 "Of Soundscapes and Blackface. From Fools to Foster", Burnt Cork: Traditions and Legacies of Blackface Minstrelsy. Stephen Johnson (editor). Capítulo 2. Amherst y Boston: University of Massachusetts Press, pp. 51-72.

COUYOUMdjian, JuAn Ricardo

2000 "El alto comercio de Valparaíso y las grandes casas extranjeras, 1880-1930. Una aproximación”, Historia, 33, pp.63-99

Cussen, Celia

2006 "El paso de los negros por la historia de Chile", Cuadernos de Historia, 25 (marzo), pp.45-58. https://cuadernosdehistoria.uchile.cl/index.php/CDH/article/view/47229/49223

Daponte, Jean Franco

2019 "Aunque no suena tan negro, es música de negros. Presencia y aporte de los esclavos africanos a la música tradicional del Norte Grande de Chile”. Tesis doctoral en musicología. Universidad de Valladolid.

Davis, Tracy C.

2013 “I long for my home in kentuck': Christy's minstrels in mid-19th-century Britain”, TDR-The Drama Review - A Journal of Performance Studies, LVII/2, pp. 39-65 https://doi.org/10.1162/ DRAM-a-00260

De la Guardia, Carmen

2012 Historia de los Estados Unidos. Madrid: Sílex Ediciones.

DENorA, TIA

2004 Music in Everyday Life. Cambridge: Cambridge University Press.

Domingo, DANIEL

2017 "Los sonidos de la esclavitud. Las canciones esclavas en los Estados Unidos". Trabajo final de Máster en Estudios Americanos. Facultad de Geografía e Historia. Universidad de Sevilla.

2021 "Afrodescendencia negada. Ocultamiento del ser y apropiación del aporte negro en Chile. Una aproximación histórico-musical”, A Contracorriente: una revista de estudios latinoamericanos, XVIII/2 (invierno), pp. 213-238.

Donoso, Carlos

2017 "Marginalidad y vanguardia en la posguerra: los inicios del teatro crítico en Chile (18831913)", Anuario de Estudios Americanos, LXXIV/2, pp. 705-728. DOI: 10.3989/aeamer.2017.2.11

Donoso, Carlos y María Gabriela Huidobro

2015 "La patria en escena: El teatro chileno en la guerra del Pacífico", Historia, XLVIII/1 (enero/ junio), pp.77-97. DOI: https://doi.org/10.4067/S0717-71942015000100003

Douglass, Frederick

1846 Narrative of the life of Frederick Douglass, an American slave. 3a ed. Wortley: Printed by Joseph Baker.

1855 My bondage and my freedom. Auburn: Miller, Orton \& Mulligan.

Du Bois, William E. B.

2007 The Souls of Black Folk. Brent H. Edwards (editor). Nueva York: Oxford University Press.

Gioia, TED

2010 Blues : la música del Delta del Mississippi. Madrid: Turner.

GRAHAM, SANDRA J.

2018 Spirituals and the Birth of a Black Entertainment Industry. Urbana: University of Illinois Press. 
Green, Alan W. C.

1970 "Jim Crow," “Zip Coon”: The northern origins of Negro minstrelsy", The Massachusetts Review, XI/2 (primavera), pp.385-397. DOI:10.2307/25087995

Johnson, STEPhen B.

2012a "Introduction: The persistance of Blackface and the Minstrel tradition", Burnt Cork: Traditions and Legacies of Blackface Minstrelsy. Stephen Johnson (editor). Amherst y Boston : University of Massachusetts Press, pp. 1-17.

2012b "Death and the Minstrel. Race, Madness, and Art in the Last (W) Rites of Three Early Blackface Performers", Burnt Cork: Traditions and Legacies of Blackface Minstrelsy. Stephen Johnson (editor). Capítulo 3. Amherst y Boston: University of Massachusetts Press, pp. 73-103.

LEgNini, Jessica H.

2011 “A 'genuine display of Ethiopian life': the Virginia Minstrels at the Manchester Athenaeum”, Popular Entertainment Studies, II/2, pp. 35-54.

LOTT, ERIC

2013 Love and Theft : Blackface Minstrelsy and the American Working Class. Oxford: Oxford University Press.

Mahar, William J.

1999 Behind the Burnt Cork Mask : Early Blackface Minstrelsy and Antebellum American Popular Culture. Urbana: University of Illinois Press.

Menanteau, Álvaro

2006 Historia del jazz en Chile. 2a ed. Santiago: Ocho Libros Editores.

MÉndez, Luz María

1987 "Paisaje y costumbres recreativas en Chile. Valparaíso en el siglo XIX”, Historia, 22, pp.151-188.

MORAles, OMAR

2010 "El esclavo negro Juan de Vera cantor, arpista y compositor de la Catedral de Puebla (florevit 1575-1617)”, Música y Catedral: nuevos enfoques, viejas temáticas. Jesús Alfaro Cruz y Raúl Torres Medina (coordinadores). Capítulo 2. Ciudad de México: Universidad Autónoma de México, pp. 43-60.

NoRThup, SOLOMON

1859 Twelve Years a Slave. Narrative of Solomon Northup, a Citizen of New-York, Kidnapped in Washington City in 1841, and Rescued in 1853, from a Cotton Plantation near the Red River in Louisiana. Nueva York: C.M. Saxton.

Pereira Salas, Eugenio

1941 Los orígenes del arte musical en Chile. Santiago: Universidad de Chile.

1948 "El rincón de la historia: La llegada de los 'Negro Spirituals' a Chile”, Revista Musical Chilena, IV/31, p. 68.

1957 Historia de la música en Chile: (1850-1900). Santiago: Universidad de Chile.

Pinochet, Josefina

2012 "La colonia británica en Valparaíso: Permanencia de una identidad comunitaria en el siglo XX”, Intus-Legere Historia, CI/2, pp. 115-133. DOI:10.15691/07176864.2012.010

Piña, JUAN ANDRÉs

2009 Historia del teatro en Chile 1890-1940. Santiago: RIL editores

Ponce de León, Macarena; Francisca Rengifo y Ernesto San Martín

2010 “Demanda social por educación? Estadística, sociedad y alfabetización a partir del Censo de la República de 1854”. Revista Pensamiento Educativo, 46-47, pp. 303-316.

RONDÓN, VÍCTOR

2014 "Música y negritud en Chile: De la ausencia presente a la presencia ausente ", Latin American Music Review, XXXV/1, pp.50-87. DOI: 10.7560/LAMR35103 
Sánchez, Alfredo; JoaQuín Bosque y Cecilia Jiménez

2009 "Valparaíso: su geografía, su historia y su identidad como Patrimonio de la Humanidad", Estudios Geográficos, LXX/266, pp. 269-293. DOI:10.3989/estgeogr.0445

SCOTT, DEREK B.

2012 Sounds of the Metropolis: The Nineteenth-century Popular Music Revolution in London, New York, Paris, and Vienna. Nueva York: Oxford University Press.

TOLL, Robert C.

1971 "From Folktype to Stereotype: Images of Slaves in Antebellum Minstrelsy", Journal of the Folklore Institute, VIII/1, pp. 38-47.

1977 Blacking up : the Minstrel Show in Nineteenth-century America. Nueva York: Oxford University Press.

WATERHOUSE, Richard

1985 "The Internationalisation of American Popular Culture in the Nineteenth Century: The case of the Minstrel show", Australasian Journal of American Studies, IV/1, pp.1-11. DOI: $10.2307 / 41053377$

WinANS, RoBert B.

1996 "Early Minstrel Show Music, 1843-1852", Inside the Minstrel Mask: Readings in Nineteenth-century Blackface Minstrelsy. Annemarie Bean, James V. Hatch y Brooks MacNamare (editores). Hanover y Londres: Wesleyan University Press, pp. 141-162.

Periódicos

El Ferrocarril, V/1488 (13 de octubre, 1860)

El Ferrocarril, V/1490 (16 de octubre, 1860)

El Ferrocarril, V/1491 (17 de octubre, 1860)

El Ferrocarril, V/1498 (25 de octubre, 1860)

El Ferrocarril, V/1499 (26 de octubre, 1860)

El Ferrocarril, V/1500 (27 de octubre, 1860)

El Mercurio de Valparaíso, XXXIII/9904 (5 de septiembre, 1860)

El Mercurio de Valparaíso, XXXIII/9905 (6 de septiembre, 1860)

El Mercurio de Valparaíso, XXXIII/9906 (7 de septiembre, 1860)

El Mercurio de Valparaíso, XXXIII/9907 (8 de septiembre, 1860)

El Mercurio de Valparaíso, XXXIII/9908 (10 de septiembre, 1860)

El Mercurio de Valparaíso, XXXIII/9910 (12 de septiembre, 1860)

El Mercurio de Valparaíso, XXXIII/9912 (14 de septiembre, 1860)

El Mercurio de Valparaíso, XXXIII/9917 (24 de septiembre, 1860)

El Mercurio de Valparaíso, XXXIII/9921 (28 de septiembre, 1860)

El Mercurio de Valparaíso, XXXIII/9923 (1 de octubre, 1860)

El Comercio, XXII/6710 (24 de diciembre, 1860)

Programas de Teatro

Programa de los Cantores Africanos, Teatro Municipal. 13 de octubre de 1860. Biblioteca Nacional, sección chilena. Título: Teatro de Chile (1828-1867). Rollo LCH 47d. 
Programa de los Cantores Africanos, Teatro Municipal. 17 de octubre de 1860. Biblioteca Nacional, sección chilena. Título: Teatro de Chile (1828-1867). Rollo LCH 47d

Programa de los Cantores Africanos, Teatro Municipal. 28 de octubre de 1860. Biblioteca Nacional, sección chilena. Título: Teatro de Chile (1828-1867). Rollo LCH 47d. 